\title{
Baicalein inhibits acinar-to-ductal metaplasia of pancreatic acinal cell AR42J via improving the inflammatory microenvironment
}

\author{
Wei-Ling $\mathrm{Pu}^{1}$ (D) | Ying-Ying Luo ${ }^{1}$ | Ru-Yu Bai ${ }^{1}$ | Ao-Wei Guo ${ }^{1}$ | \\ Kun Zhou 1,2,3,4 | Yun-Sha Zhang5,6 | Lin Miao ${ }^{1,2,3,4,7}$ | Curzio Rüegg ${ }^{6}$ | \\ Micheal O. Hottiger ${ }^{7}$ | Xiu-Mei Gao ${ }^{1,2,3,4}$ | Li-Kang Sun ${ }^{1,2,3,4,5}$
}

${ }^{1}$ Institute of Traditional Chinese Medicine, Tianjin University of Traditional Chinese Medicine, Tianjin, China

2 Tianjin Key Laboratory of Chinese medicine Pharmacology, Tianjin University of Traditional Chinese Medicine, Tianjin, China

${ }^{3}$ Key Laboratory of Pharmacology of Traditional Chinese Medical Formulae, Ministry of Education, Tianjin University of Traditional Chinese Medicine, Tianjin, China

${ }^{4}$ Key Research Laboratory of Prescription Compatibility among Components, Tianjin University of Traditional Chinese Medicine, Tianjin, China

${ }^{5}$ School of Integrative Medicine, Tianjin University of Traditional Chinese Medicine, Tianjin, China

${ }^{6}$ Pathology Unit, Faculty of Sciences, Department of Medicine, University of Fribourg, Fribourg, Switzerland

7 Department of Molecular Mechanisms of Disease, University of Zurich-Irchel, Zurich, Switzerland

Correspondence

Li-Kang Sun, School of Integrative Medicine, Tianjin University of Traditional Chinese Medicine, 88 Yuquan Road, Nankai District,

Tianjin 300193, China.

Email: likang.sun@bluewin.ch

Funding information

Sino Swiss Science and Technology

Cooperation programme, Grant number: EG

07-032016; Sino Swiss Science and

Technology Cooperation programme,

Grant number: EG 05-032015; National

Natural Science Foundation of China,

Grant number: 81630106; Tianjin University

of Traditional Chinese Medicine Foundation
Pancreatic ductal adenocarcinoma (PDAC) is one of the most aggressive cancers. Recent research has demonstrated that chronic pancreatitis $(C P)$ is associated with an increased risk of PDAC, partly due to acinar-to-ductal metaplasia (ADM). Baicalein has been shown to exert anti-inflammatory and anti-tumor effects for $C P$ or PDAC, respectively. The aim of our study was to investigate the effect of baicalein, and the putative underlying mechanism, on inflammatory cytokinesinduced ADM of rat pancreatic acinar cell line AR42J. To investigate ADM and baicalein effects in vitro, AR42J were treated with recombinant rat Tumor Necrosis Factor alpha (rTNFa) with or without baicalein for 5 days. Results showed that rTNFa-induced AR42J cells switched their phenotype from dominantly amylase-positive acinar cells to dominantly cytokeratin 19-positive ductal cells. Moreover, expression of the transcripts for TNF $\alpha$ or Hes-1, a Notch target, was up-regulated in these cells. Interestingly, baicalein reduced the population of ADM as well as cytokines gene expression but not Hes-1. Baicalein inhibited NF-KB activation induced by rTNFa in AR42J, but no effect on Notch 1activation. Moreover, baicalein suppressed the secretion of TNFa and Nitric Oxide (NO) in macrophages stimulated with LPS and further inhibited ADM of conditional medium-treated AR42J cells. Baicalein also suppressed the inflammatory response of LPS-activated macrophages, thereby inhibited ADM of AR42J by altering their microenvironment. Taken together, our study indicates that baicalein reduces $r T N F a$-induced ADM of AR42J cells by inhibiting NF-KB activation. It also sheds new light on Chinese material medica therapy of pancreatitis and thereby prevention of PDAC.

KEYWORDS

acinar-to-ductal metaplasia, baicalein, inflammatory microenvironment, NF-KB, Notch-1 


\section{1 | INTRODUCTION}

Pancreatic ductal adenocarcinoma (PDAC) is a highly aggressive cancer. Even with early diagnosis, nearly all patients die from the disease within 1-2 years after diagnosis (Johnston et al., 2016). The high mortality of full blown PDAC, calls for strategies for its prevention. Many risk factors are associated with the development of PDAC, the most common of which is pancreatitis (Li, Xie, Wolff, \& Abbruzzese, 2004). Clinical trials had shown that the incidence of PDAC in patients with pancreatitis was greatly increased (Krejs, 2010; Lowenfels \& Maisonneuve, 2006). Recently, it has been shown that inflammation contributes to development of PDAC as pancreatic acinar cells may undergo transdifferentiation toward a ductal phenotype (acinar-to-ductal metaplasia, ADM), progress to pancreatic intraepithelial neoplasia (PanIN) and eventually form invasive PDAC (Lardon \& Bouwens, 2005; Shi et al., 2009). During pancreatitis, these metaplasia duct-like cells dampen the expression of pancreatic enzymes but increase the expression of keratin (Means \& Logsdon, 2016). ADM was detected in patients with pancreatitis, in a model of chronic pancreatitis (WBN/Kob rats) and in caerulein-induced pancreatitis in mice, consistent with a role of the inflammatory microenvironment in promoting tumorigenesis (Reding et al., 2009; Seleznik et al., 2012). On the other hand, macrophage infiltration, and the inflammatory response of pancreatic acinar cells can induce pancreatic ADM and increase the incidence of PDAC (Helm et al., 2014; Liou et al., 2013; Xue et al., 2015). Macrophage-derived proinflammatory cytokines, such as TNFa, are potent drivers of ADM.

The root of Scutellaria baicalensis Georgi, listed in the Chinese Pharmacopoeia, is one of the commonly used traditional Chinese herbs for the treatment of pancreatitis in China and other East Asian countries. Baicalein (5, 6, 7-trihydroxy-2-phenyl-4H-1-benzopyran-4one), one of its derived product, is a flavonoid with a defined chemical structure, reported to possess excellent anti-inflammatory, and antitumor activities (Gao, Snyder, Smith, \& Chen, 2016). Baicalein could alleviate experimental pancreatitis by inhibiting the expression of pancreatic enzyme and cytokines via multiple pathways ( $\mathrm{Li}$ et al., $2015 \mathrm{a}$, b). To the best of our knowledge, there are only a few previous reports on the effects of baicalein on pancreatic ADM mainly focused on its effect on apoptosis and proliferation (Cathcart et al., 2016; Chen et al., 2014; Guo et al., 2015; He et al., 2017; Lian et al., 2017; Zhang et al., 2013). Our study was initiated with the purpose to investigate the effect of baicalein, and the putative mechanism involved, on ADM induced by inflammatory cytokines, using the rat pancreatic acinar cell line AR42J as in vitro model. Results issued from this study may provide new sights into the potential role of baicalein in controlling pancreatitis or prevention of PDAC.

\section{2 | MATERIALS AND METHODS}

\section{1 | Cell lines, antibodies, and reagents}

RAW264.7 murine macrophages cells, obtained from the Cell Culture Center of the Chinese Academy of Medical Sciences (Beijing, China), were maintained as described before (Sun, Wahl, Bilic, \& Wuthrich, 2001). For the determination of NO and TNF- $a$ concentrations, cells were plated at a density of $2.5 \times 10^{5}$ cells $/ \mathrm{ml}$ in 24 -well plates for $24 \mathrm{hr}$ and then treated with LPS $(0.5 \mu \mathrm{g} / \mathrm{ml})$ in the presence or absence of different concentrations of baicalein for $18 \mathrm{hr}$.

AR42J (ATCC ${ }^{\circledR}$ CRL-1492 ${ }^{\mathrm{TM}}$ ) rat exocrine pancreas cells, obtained from the American Type Culture Collection (ATCC, Manassas, VA), were maintained as described before (Sun et al., 2007). For monitoring AR42J phenotypical transdifferentiation and related gene and protein expression, cells were routinely plated at a density of $8 \times 10^{4}$ cells $/ \mathrm{ml}$ in 12-well plates or on coverslips for $24 \mathrm{hr}$ and then treated with baicalein treated macrophage-conditional medium or recombinant rat $\mathrm{TNFa}(50 \mathrm{ng} / \mathrm{ml})$ in the presence or absence of baicalein $(40 \mu \mathrm{M})$ for 5 days. Culture medium replaced every other day.

Recombinant rat TNFa (rTNFa) was purchased from PeproTech Inc. (Rocky Hill, NJ). Primary antibodies against phosphorylated ІкBa ( $\mathrm{p}-\mathrm{I}_{\mathrm{B}} \mathrm{B}$ ), ІкBa, NF-кB, amylase, cytokeratin 19, and cleaved-Notch 1 were purchased from CST Inc. (Danvers, MA). Mouse TNFa DuoSet ELISA kit was purchased from R\&D Systems (Minneapolis, MN). Griess Reagent was purchased from Beyotime Institute of Biotechnology (Shanghai, China). Lipopolysaccharide (LPS) was purchased from SigmaAldrich (St Louis, MO). Baicalein (purity exceed 98\%), purchased from Top High Bio Technology Co., Ltd. (Nanjing, China), was dissolved in dimethylsulfoxide (DMSO) and further diluted in cell culture medium. The final DMSO concentration did not exceed $0.1 \%(\mathrm{v} / \mathrm{v})$.

\section{2 | Cell viability assay}

Cell viability of AR42J or RAW264.7 treated with baicalein was measured with MTT (3-(4, 5-dimethylthiazol-2-yl)-2, 5-diphenyl tetrazolium bromide) test. After treatment with baicalein or rTNFa for 5 days, cells were incubated with MTT reagent (dissolved in PBS at a final concentration of $0.5 \mathrm{mg} / \mathrm{ml}$ ) at $37^{\circ} \mathrm{C}$ for $4 \mathrm{hr}$. After rinsing of the well, DMSO was added to all wells and mixed thoroughly to dissolve the dark blue crystals. Plates were read on a Microplate Reader (Molecular Devices, Sunnyvale, CA), at $570 \mathrm{~nm}$ wavelength against a reference wavelength of $630 \mathrm{~nm}$.

\section{3 | Immunofluorescence staining}

Cells were cultured on glass coverslips, washed with phosphatebuffered saline (PBS) to remove serum, fixed with $4 \%$ paraformaldehyde (PFA), permeabilized with $0.2 \%$ Triton $\mathrm{X}-100$ for $5 \mathrm{~min}$, and blocked for nonspecific binding of IgG with $3 \%$ Bovine Serum Albumin (BSA) for $30 \mathrm{~min}$. The specific primary antibodies, goat anti-rat amylase and rabbit anti rat cytokeratin 19 were used at 1:200 and 1:200 dilutions in PBS, respectively and incubated at $4^{\circ} \mathrm{C}$ overnight. After a washing step, the coverslips were incubated with FITC- or TRITCconjugated secondary antibody for $1 \mathrm{hr}$. DAPI solution $(125 \mu \mathrm{g} / \mathrm{ml})$ was added when samples were incubated with the secondary antibodies. The coverslips were washed three times in PBS. Images were taken with Nikon TiU microscope (Nikon, Amstelveen, Netherlands). 


\subsection{RNA isolation and real-time PCR}

Total RNA was isolated from AR42J cells using TRIzol reagent according to the manufacturer's instructions (Invitrogen Life Technologies, Carlsbad, CA). Total RNA samples were pretreated with DNase to eliminate residual genomic DNA. Total RNA $(2 \mu \mathrm{g})$ was reversetranscribed to cDNA using GoScript ${ }^{\mathrm{TM}}$ Reverse Transcription System (Promega Corporation, Madison, WI) according to manufacturer's instructions. Briefly, the reaction was incubated in steps of $25^{\circ} \mathrm{C}$ for $5 \mathrm{~min}, 42^{\circ} \mathrm{C}$ for $60 \mathrm{~min}, 70^{\circ} \mathrm{C}$ for $15 \mathrm{~min}$, and held at $4^{\circ} \mathrm{C}$. Real-time RTPCR was performed using SYBR Green PCR Master Mix reagent kits (Promega Corporation, Madison, WI), performed in a real-time $\mathrm{C} 1000$ Touch $^{\text {TM }}$ Thermal Cycler with a CFX96 real time system (Bio-rad, Hercules, CA) with the following thermocycler program: $95^{\circ} \mathrm{C}$ for $20 \mathrm{~s}$, 40 cycles of $95^{\circ} \mathrm{C}$ for $5 \mathrm{~s}$, and $60^{\circ} \mathrm{C}$ for $60 \mathrm{~s}$. Specific primer sets for rat TNFa, Hes-1, and $\beta$-actin were as follows: TNFa: Forward: $5^{\prime}-3^{\prime}-$ GAAGAGAACCTGGGAGTAGATAAGG, Reverse: 5'-3'-GTCGTAGCAAACCACCAAGC; Hes-1: Forward: 5'-3'-CAACACGACACCGGACAAAC, Reverse: 5'-3'-GGAATGCCGGGAGCTATCTT; $\beta$-actin: Forward: 5'-3'-GTGACGTTGACATCCGTAAAGA, Reverse: 5'-3'GCCGGACTCATCGTACTCC. The mRNA expression levels were determined relative to a blank control after normalizing to $\beta$-actin using the $2^{-\triangle \triangle C T}$ method. Each data point was carried out in triplicates.

\section{5 | Protein extraction and immunoblotting}

After treatment with $\mathrm{rTNFa}$, in the presence or absence of baicalein, AR42J cells were washed twice with cold PBS, lysed in RIPA buffer (50 mM Tris- $\mathrm{HCl}, 150 \mathrm{mM} \mathrm{NaCl}$, and 1\% NP-40) containing proteinase and phosphatase inhibitors, and then centrifuged at 12,000g for $10 \mathrm{~min}$ at $4^{\circ} \mathrm{C}$. The supernatants were collected and stored at $-80^{\circ} \mathrm{C}$ until analysis.

Nucleoprotein extraction was performed using the nucleoprotein extraction kit according to the manufacturer's instructions (Sangon Biotech, Shanghai, China). AR42J cells were washed twice with cold PBS, lysed in cold hypotonic buffer for $10 \mathrm{~min}$ and centrifuged at $800 \mathrm{~g}$ for $5 \mathrm{~min}$ at $4^{\circ} \mathrm{C}$. The pellet was collected and then lysed in cold lysis buffer (with proteinase and phosphatase inhibitors), and then centrifuged at $12,000 \mathrm{~g}$ for $10 \mathrm{~min}$ at $4^{\circ} \mathrm{C}$. The supernatants were collected and stored at $-80^{\circ} \mathrm{C}$ until analysis.

Protein concentrations were determined using the Bradford method. Samples were diluted to $3 \mathrm{mg} / \mathrm{ml}$ with PBS and $5 \times$ SDSPAGE sample loading buffer, and heated at $95^{\circ} \mathrm{C}$ for $5 \mathrm{~min}$ before loading. Thirty microgram of total protein were loaded per lane on Invitrogen ${ }^{\mathrm{TM}}$ NuPAGE ${ }^{\mathrm{TM}}$ Bis-Tris gels (10\%) and subsequently transferred to polyvinylidenedifluoride (PVDF) membranes (Millipore, MA). Membranes were blocked with $5 \%(\mathrm{w} / \mathrm{v})$ skimmed milk in TBST buffer at room temperature for $2 \mathrm{hr}$, followed by incubation with specific primary antibodies for $\beta$-actin, $\mathrm{p}-\mathrm{I}_{\mathrm{K}} \mathrm{Ba}$, ІкBa, nucleus NF-кB p65 (n-p65), or cleaved-Notch 1 (c-Notch 1), overnight at $4^{\circ} \mathrm{C}$. After washing three times with TBST, membranes were subsequently incubated with corresponding secondary antibodies conjugated with horseradish peroxidase $(1: 10,000)$ for $2 \mathrm{hr}$ at room temperature. Bound antibodies were detected using an enhanced chemiluminescence (ECL) system (Promega Corporation, Madison, WI), according to manufacturer's instructions. Luminescence intensities were quantified using Imaging Systems analysis software (VersaDoc Mp5000, BIO-RAD).

\section{6 | Measurement of TNFa and NO production}

RAW264.7 cells were incubated with or without LPS in the absence or presence of baicalein for $18 \mathrm{hr}$. The NO and TNFa concentrations in culture medium were measured using the Griess reagent system and mouse TNFa ELISA kit, respectively, according to the manufacture's protocol. Macrophage-conditioned medium (CM) were as following: Control-CM, RAW264.7 cells cultured in the absence of LPS; LPS-CM, RAW264.7 cells cultured in the presence of LPS; BaicaleinCM, RAW264.7 cells cultured in the presence of LPS and Baicalein. CMs were collected, centrifuged at $1,500 \mathrm{~g}$ for $10 \mathrm{~min}$., and the supernatants stored at $-80^{\circ} \mathrm{C}$ for further use.

\section{7 | Statistical analysis}

All experiments were performed in triplicate, and each experiment was repeated at least three times. All values represent mean \pm SD. Data were analyzed by one-way analysis of variance and $t$-test was used for comparison between any two groups. $p$ value of $<0.05$ was considered as statistic significant different.

\section{3 | RESULTS}

\subsection{Effect of baicalein on cell viability of AR42J and RAW264.7}

The viability of cultured cells was monitored using the MTT assay. Treatment of AR42J cells for 5 days with different concentration of baicalein or RAW274.7 macrophages for $18 \mathrm{hr}$ revealed no measurable difference in viability for baicalein concentrations 5-40 $\mu \mathrm{M}$ compared to control samples. However, at $80 \mu \mathrm{M}$, baicalein decreased the viability of AR42J and RAW274.7 cells by approx. 30\% (Figures 1a and 1B).

\subsection{Baicalein inhibits rTNFa induced ADM of pancreatic acinar AR42J cells}

Under normal culture conditions AR42J cell are predominantly amylase positive acinar cells. When AR42J cells were treated with $50 \mathrm{ng} / \mathrm{ml} \mathrm{rTNFa}$, the phenotype of AR42J progressively converted into a ductal phenotype after 5 days exposure (Figure 2a). AR42J switched phenotype from dominantly amylase-positive acinary cells (FITC labeled) to dominant cytokeratin-19 (CK-19)-positive ductal cells (TRITC labeled) compared to untreated amylase positive AR42J cells. Concomitant treatment with baicalein, markedly reduced the fraction of CK-19-positive population of ductal AR42J cells induced by rTNFa treatment. Furthermore, decreased expression of amylase and CK-19 


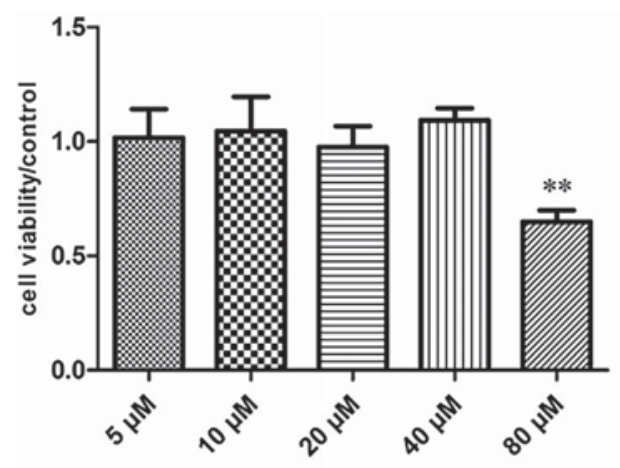

(a)

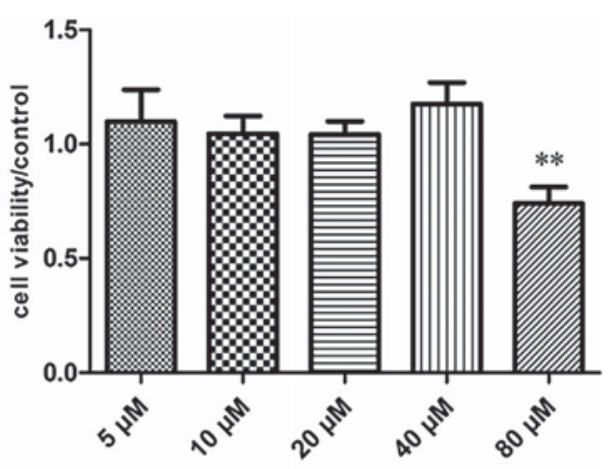

(b)

FIGURE 1 Effect of baicalein on the viability of AR42J (a) and RAW264.7 cells (b). AR42J cells were treated with baicalein for 5 days, and RAW264.7 cells for $18 \mathrm{hr}$, respectively. ${ }^{* *} p<0.01$

(Amylase/CK-19) by baicalein in rTNFa-treated cells also demonstrated the results (Figure $2 \mathrm{~b}$ ).

\section{3 | Baicalein inhibits TNFa but not Hes-1 gene expression in rTNFa-treated AR42J cells}

TNFa can trigger the expression of various inflammatory mediators in AR42J cells (Robinson, Vona-Davis, Riggs, Jackson, \& McFadden, 2006; Sun et al., 2007). To examine whether baicalein could inhibit the expression of some inflammatory mediator, expression of TNF $\alpha$ mRNA was monitored by RT-PCR analysis after 5 days exposure to rTNFa. TNF $\alpha$ expression was significant increased after 5 days of rTNFa treatment compared to control cells, and baicalein significantly inhibited this induction (Figure 3a). It was reported, that the Notch target gene Hes-1 (hairy and enhancer of split 1) was supregulated during ADM (Halbrook \& Crawford, 2015). A significant up-regulation of Hes-1 was also observed in rTNFa-treated AR42J cells; however, baicalein had no effects on it upregulation (Figure $3 b$ ).

These results indicate that baicalein inhibits the expression TNF $\alpha$ mRNA induced by rTNFa in AR42J cells, while it does not inhibit rTNFa-induced and Notch-mediated Hes-1 expression.

\subsection{Baicalein prevents rTNFa induced ІкBa degradation and NF-KB translocation, but not Notch activation in AR42J cells}

To further investigate the mechanisms of baicalein inhibition of TNFinduced $A D M$, we monitored the degradation of $1 \kappa \mathrm{Ba}$, the nuclear translocation of the NF-KB subunit p65 and the cleavage of Notch 1 by Western blotting analysis of total cellular or nuclear extracts. Treatment of AR42J cells with rTNFa, resulted in increased ІкBa
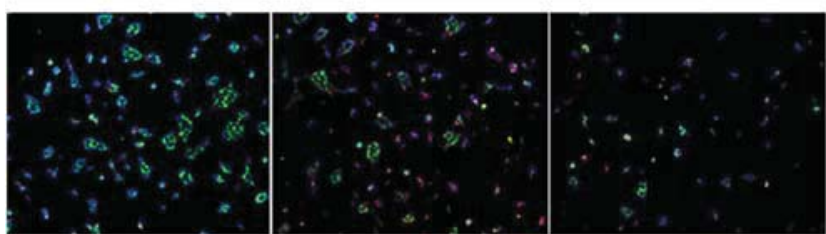

$10 \times$
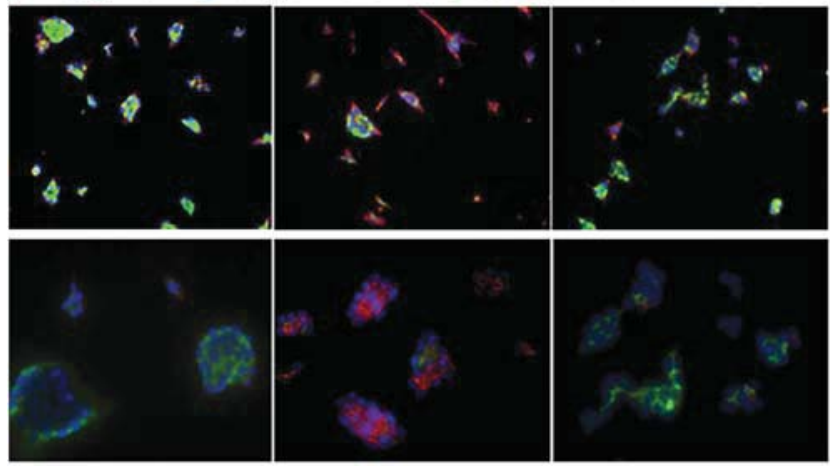

Control

rTNF $\alpha$

(a)

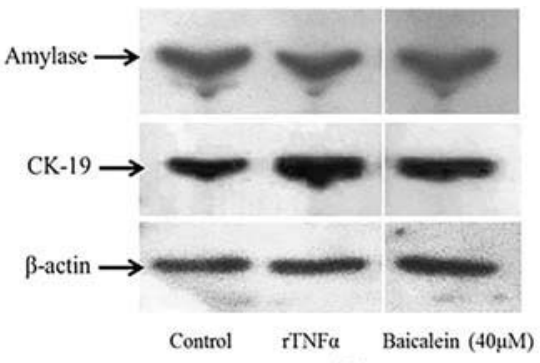

(b)

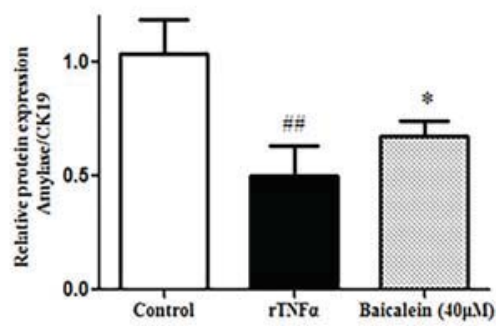

(c)

FIGURE 2 Effect of Baicalein on phenotypical switch of AR42J cells. (a) Immunofluorescence staining of amylase (green), CK-19(red), and DAPI of AR42 cells. (b) Amylase and CK-19 protein expression monitored by Western blotting. (c) Quantification of amylase and CK-19 proteins detected by Western blotting (panel b). ${ }^{*} p<0.05$ versus rTNFa treatment only; ${ }^{\# \#} p<0.01$ versus control 


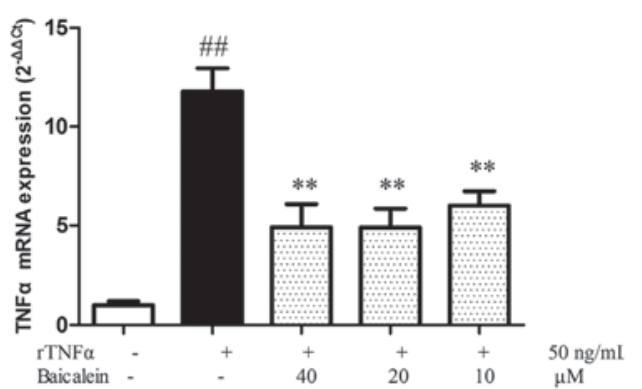

(a)

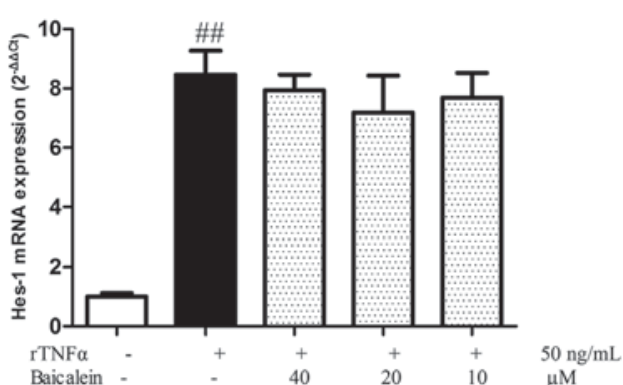

(b)

FIGURE 3 Effect of Baicalein on rTNFa induced gene transcription in AR42J cells. AR42J cells were exposed to rTNFa for 5 days, and TNFa (a) and Hes-1 (b) mRNA levels were measured by RT-PCR. ${ }^{* *} p<0.01$ versus rTNFa treatment only; ${ }^{\# \#} p<0.01$ versus control

degradation, phosphorylation of $1 \mathrm{KBa}(\mathrm{p}-\mathrm{I} \mathrm{\kappa Ba})$, and $\mathrm{p} 65$ translocation to the nucleus (n-p65) (Figure 4a), which indicated that NF-kB signaling pathway was activated by TNF treatment. Cleaved Notch 1 (c-Notch 1 ) expression was increased during ADM. Baicalein $(40 \mu \mathrm{M})$ inhibited the degradation of $1 \mathrm{kB} a$, phosphorylation of $1 \mathrm{KBa}$, and $\mathrm{p} 65$ translocation to the nucleus. However, baicalein treatment did not inhibit the cleavage of Notch-1. Effects on protein expression were consistent with the observed gene expression results.

\subsection{Baicalein inhibits LPS-induced TNFa and NO secretion in RAW264.7 cells and further inhibits macrophage-conditioned medium induced ADM in AR42J cells}

Previous work demonstrated that inflammatory environment drives $A D M$ in pancreas, and that baicalein could attenuate the inflammatory response of infiltrated macrophages (Fan et al., 2013; Strobel et al., 2007). We investigated whether baicalein could attenuate LPSinduced inflammatory response, and further inhibit AR42J ADM induced by macrophage conditioned medium. Baicalein inhibited LPSinduced NO production (Figure $5 \mathrm{a}$ ) and TNF-a protein expression (Figure 5b) in RAW264.7 cells. AR42J cells were treated with different CM (Control-CM, LPS-CM, and LPS/Baicalein-CM) for 5 days and phenotype switch was monitored by immunofluorescence double staining for amylase and CK-19 (Figure 6a). LPS-CM induced AR42J phenotype switch from amylase positive cells to $\mathrm{CK}-19$ positive cells was more pronounced than ADM induced by TNF alone. Only few amylase positive (green) cells were detected in LPS-CM group. In the LPS/Baicalein-CM treated group AR42J cells remained largely amylase positive, and only rare CK-19 positive (red) cells were detected. Changes in amylase and CK-19 protein levels were further confirmed by Western blotting analysis (Figure 6b). This indicates that baicalein

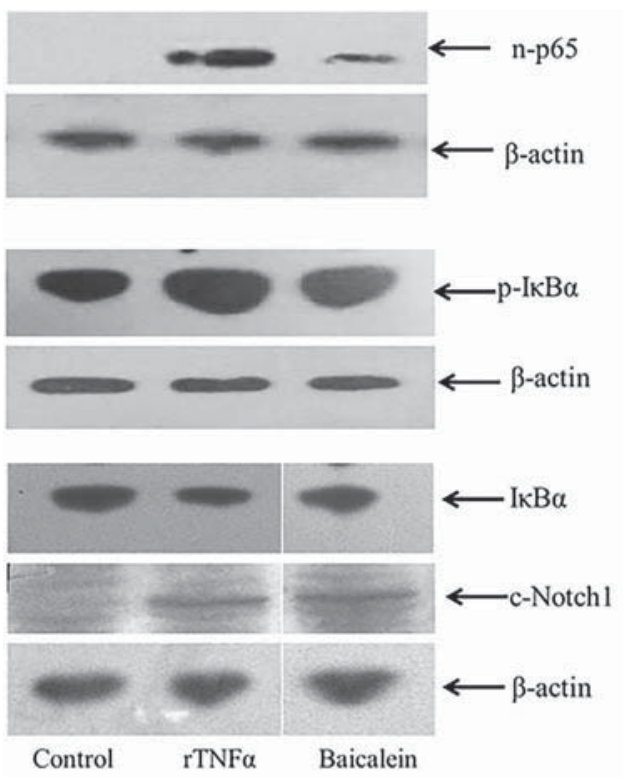

(a)
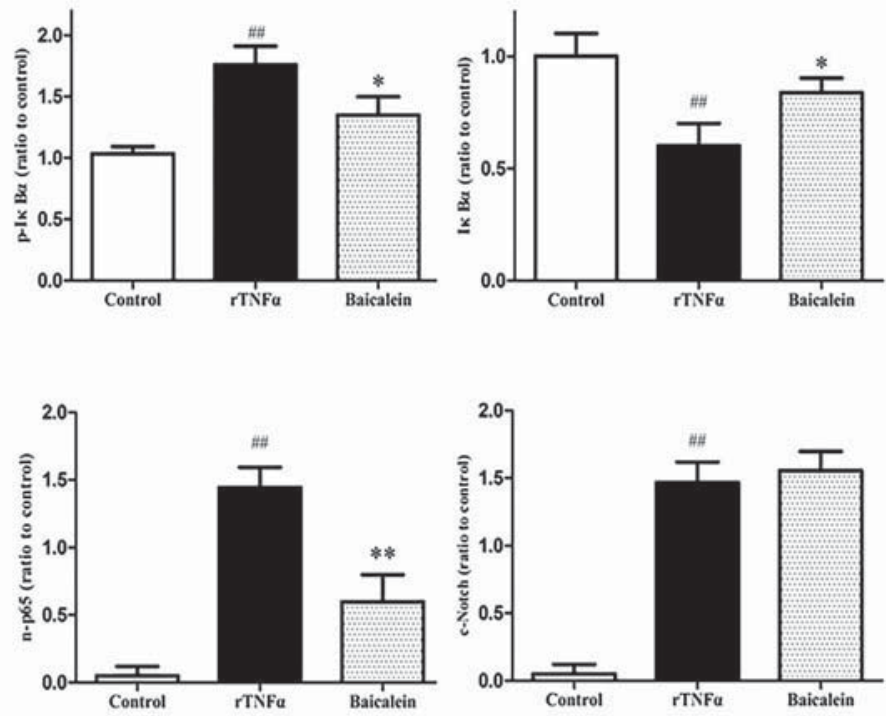

(b)

FIGURE 4 Effects of Baicalein on IKB degradation, IKBa phosphorylation, NF-KB p65 nuclear translocation, and Notch 1protein cleavage in AR42J cells. (a) AR42J cells were stimulated with rTNFa and/or baicalein. Total and nuclear proteins were analyzed by Western blotting for $\mathrm{IKB}, \mathrm{p}-\mathrm{I} \mathrm{KBa}, \mathrm{NF}-\mathrm{KB}$ p65subunit, and intracellular Notch 1protein cleavage. (b) Quantitative analysis of protein expression. ${ }^{*} p<0.05$ versus rTNFa treatment only; ${ }^{* *} p<0.01$ versus rTNFa treatment only; ${ }^{\# \#} p<0.01$ versus control. 


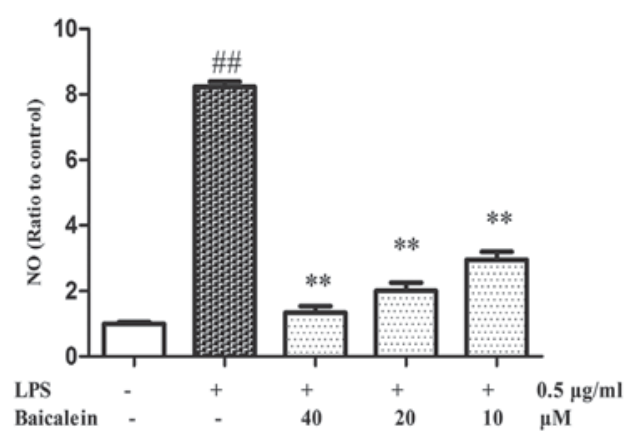

(a)

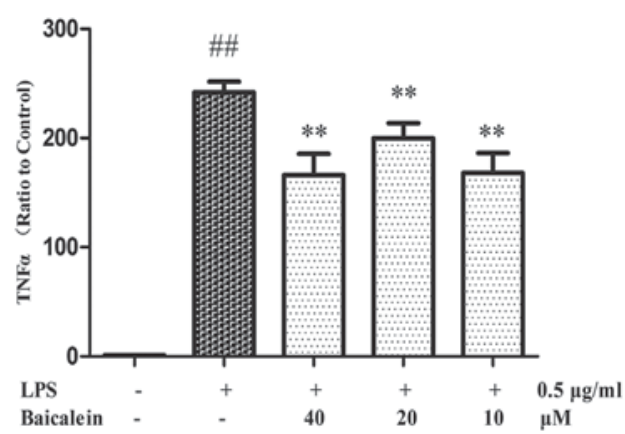

(b)

FIGURE 5 Effects of baicalein on NO release (a), and secreation of TNF- $a$ (b) in RAW264.7 cells supernatant. ${ }^{* *} p<0.01$ versus LPS treatment only; ${ }^{\# \#} p<0.01$ versus Control

suppressed inflammation-mediated ADM of AR42J cells by inhibiting LPS-induced macrophage cytokines secretion and suppressing ADM response of AR42J cells to inflammation.

\section{4 | DISCUSSION}

Metaplasia is a reversible conversion of a differentiated tissue type into another differentiated tissue in response to microenvironmental stress conditions, including chronic inflammation (Lardon \& Bouwens, 2005). The metaplasia of exocrine acinar tissue into ductal complexes (ADM) in the pancreas has been observed in different pathological conditions, most importantly in chronic pancreatitis patients. ADM was reproduced experimentally, in a caerulein-induced pancreatitis mouse model, and in multiple transgenic mouse models (Grabliauskaite et al., 2015;
Guerra et al., 2007; Lowenfels \& Maisonneuve, 2006). Metaplastic duct cells are more likely accumulate gene mutations leading to cell cycle disruption, loss of tumor suppressor and DNA repair genes and to progress to pancreatic intraepithelial neoplasia (PanIN) first and invasive PDAC later (Garcia-Carracedo et al., 2015; Shi et al., 2009). Many cytokines and activated signaling pathways may drive ADM in the inflammatory microenvironment. Previous work has shown that overexpression of growth factors in acinar cells, such as transforming growth factor $a$ (TGFa) or $\beta$ (TGF $\beta$ ), were required for the activation of Notch signaling and the induction of ADM (De La O \& Murtaugh, 2009; Miyamoto et al., 2003). Notch signaling regulates cell growth and differentiation in a wide variety of tissues. Notch pathway components and Notch target genes are upregulated in PDAC precursors (including metaplasia ductal cells) in both mouse and human, which indicates its important role in ADM (De La O \& Murtaugh, 2009). Recent study

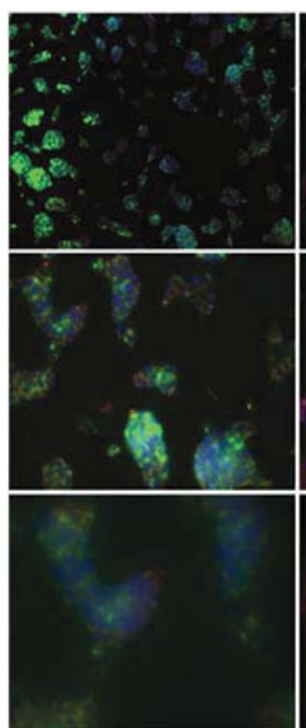

Control-CM

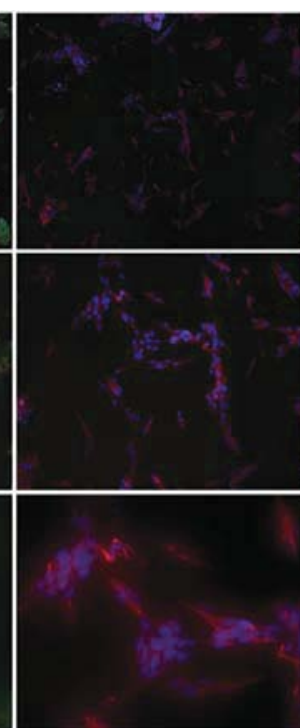

LPS-CM

(a)

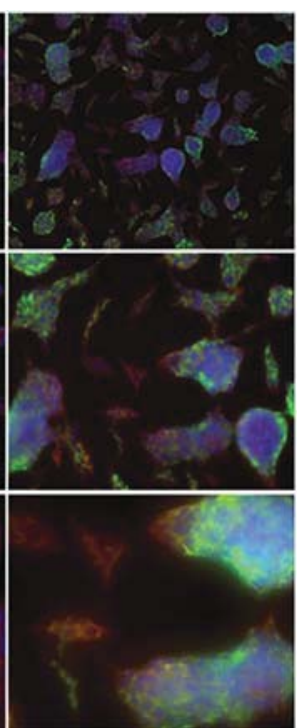

LPS/Baicalein-CM

$10 \times$

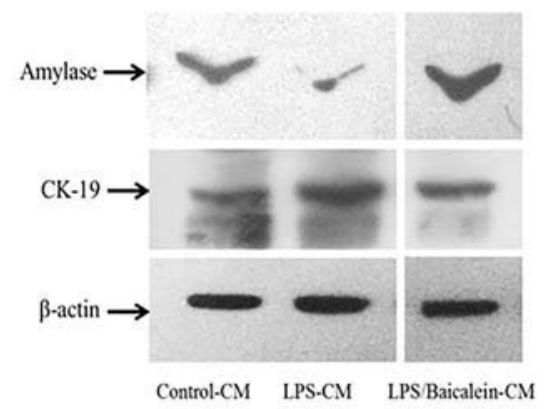

(b)

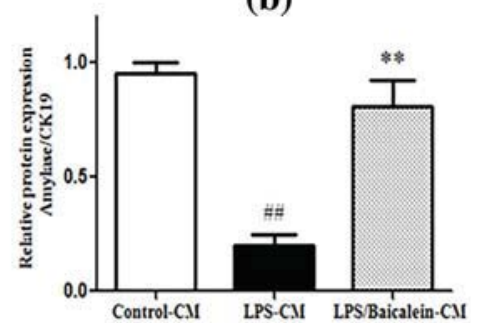

(c)

FIGURE 6 Effect of CM on phenotype switch of AR42J. (a) Immunofluorescence staining of AR42J cells. Acinar phonetype is indicated by amalyse positivity (green staining, control), ductal phenotype is indicated by CK-19 positivity (red staining). (b) The level of amylase and CK-19 protein expression. (c) Quantitative analysis of protein expression of amylase/CK-19. ${ }^{* *} p<0.01$ versus LPS-CM treatment only; ${ }^{\# \#} p<0.01$ versus control 


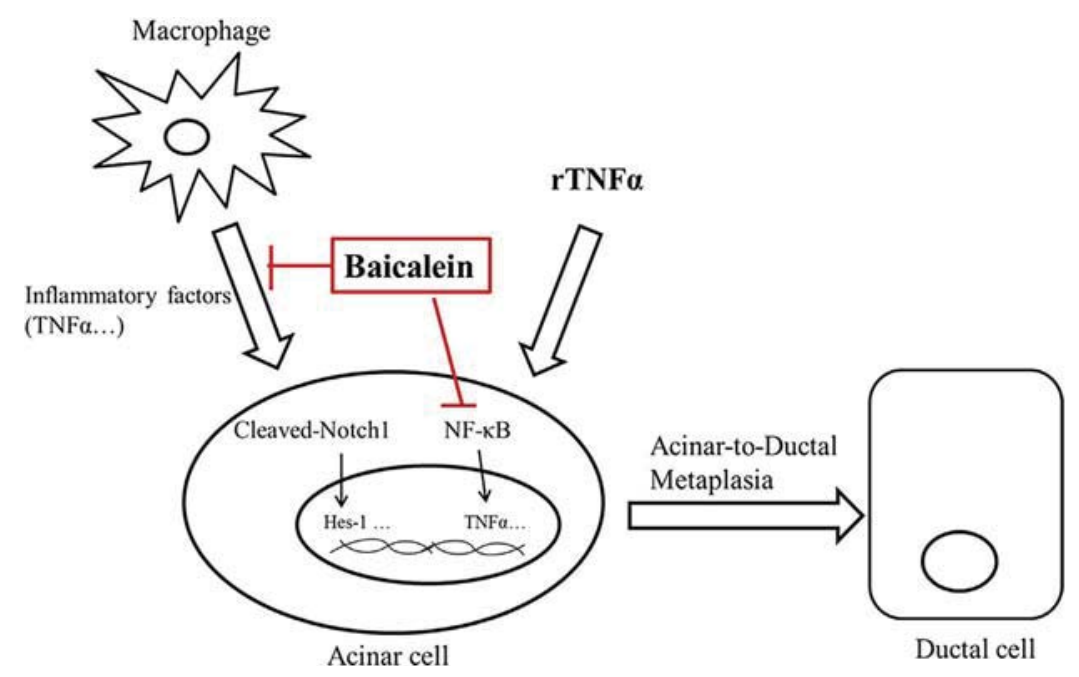

FIGURE 7 The effects and mechanism of Baicalein on ADM. Macrophage-secreted cytokines, in particular TNFa, or recombinant TNFa (rTNFa) drive pancreatic acinar-to-ductal metaplasia (ADM). NF-KB and Notch signals are activated during ADM. Baicalein directly reduced rTNFa induced ADM of AR42J by inhibitibg NF-KB activation. Baicalein also suppresses the inflammatory response of macrophages and improved the microenvironment, thereby indirectly inhibiting ADM of AR42J

showed that TNFa is overexpressed in pancreatitis and could induce ADM in acinar cells through NF-kB activation (Liou et al., 2013). Further, tumor cell- and macrophage-derived TNFa plays a profound role in pancreatitis and pancreas malignancy, and inhibition of TNFa had a protective effect (Egberts et al., 2008; Hughes et al., 1996). NF-KB is an important signaling molecule that controls multiple cellular functions, including the production of inflammatory cytokines, chemokines, and adhesion molecules. Strong activation of NF-KB is observed in many cancers including pancreatic cancer (Aggarwal \& Gehlot, 2009). Clinical data also demonstrated that NF-KB activation is more frequent in pancreatic cancers associated with chronic pancreatitis (CPPCa) than in sporadic cancers (Shimosegawa, Kume, \& Satoh, 2009). Taken together these observations indicate that TNFa and the activation of NF-KB are relevant to the pathogenesis of ADM.

Inflammatory cells, especially macrophages, are important in the progression of chronic pancreatitis (CP) and the associated increases risk of developing PDAC. During CP, injured acinar cells secreted chemokines to attract and activate macrophages, which produce various cytokines, chemokines, prostaglandins, and TGF $\beta$ to aggravate the CP or possibly induce carcinogenesis (Reding et al., 2006). Geou-Yarh Liou's research showed that macrophagesecreted cytokines such as TNFa and RANTES could drive ADM through NF-KB activation in acinar cells (Liou et al., 2013). Macrophage-targeted therapy has achieved good therapeutic effects in the treatment of CP and PDAC (Ruffell \& Coussens, 2015). Previous studied showed that baicalein, an active compound isolated from S. baicalensis Georgi, exert anti-inflammatory, and anti-tumor effects on CP and PDAC. Baicalein was shown to inhibit the inflammatory response of acinar cells and macrophages in vivo and in vitro (Li et al., 2015a; Zhou et al., 2017). Here we report results from in vitro experiments aimed at characterizing the effects of baicalein on ADM in pancreatic acinar cells induced by rTNFa and macrophages.
On the one hand, our results indicated that baicalein inhibits rTNFa-induced ADM, and this effect was associated with suppression of NF-KB activation, but not of canonical Notch 1 activation. Previous work showed that Notch 1 activation and the target gene expression were the typical characteristic of ADM. Recent research demonstrated that Notch 1 is not required for ADM in a Kras-induced PDAC model, which proved that other signaling pathway (such as inflammatory pathways) may have dominant effects on ADM (Avila, Troutman, Durham, \& Kissil, 2012). Our results suggest that inhibition of NF-kB by baicalein could reduce ADM development under inflammatory conditions. On the other hand, baicalein inhibited the secretion of TNFa and NO of LPS induced RAW264.7, and further inhibited ADM induction in pancreatic exocrine cells AR42J. The observation that CM from baicalein-treated macrophages was less effective in inducing ADM, suggesting the baicalein might also contribute to inhibit ADM indirectly, by inhibiting the pro-inflammatory activity of macrophages.

In conclusion, our results revealed that baicalein, a natural compound derived from Chinese herbal medicine, inhibits pancreatic ADM progressions through two concurrent mechanisms: First, by suppressing TNFa-induced NF-KB activation in pancreatic acinar cells and, second, by inhibiting TNFa secretion by activated macrophages (shown in Figure 7). The study provides new experimental evidence on the potential of Chinese material medica therapy for the prevention or treatment of $\mathrm{CP}$ and subsequent development of PDAC.

\section{ACKNOWLEDGMENTS}

This Project was supported by National Natural Science Foundation of China (81630106 to GXM); Natural Science Foundation Tibetan Autonomous Region of China; Sino Swiss Science and Technology Cooperation programme (EG 05-032015 to $\mathrm{MOH}$ and SLK, EG 07-032016 to RC and SLK); Tianjin University of Traditional Chinese Medicine Foundation (to SLK). 


\section{CONFLICTS OF INTEREST}

The authors declare that they have no conflicts of interest.

\section{ORCID}

Wei-Ling Pu (iD) http://orcid.org/0000-0003-1040-8424

\section{REFERENCES}

Aggarwal, B. B., \& Gehlot, P. (2009). Inflammation and cancer: How friendly is the relationship for cancer patients? Current Opinion in Pharmacology, 9, 351-369.

Avila, J. L., Troutman, S., Durham, A., \& Kissil, J. L. (2012). Notch1 is not required for acinar-to-ductal metaplasia in a model of kras-induced pancreatic ductal adenocarcinoma. PLoS ONE, 7, e52133.

Cathcart, M. C., Useckaite, Z., Drakeford, C., Semik, V., Lysaght, J., Gately, K., ... Pidgeon, G. P. (2016). Anti-cancer effects of baicalein in non-small cell lung cancer in-vitro and in-vivo. BMC Cancer, 16, 707.

Chen, F., Zhuang, M., Peng, J., Wang, X., Huang, T., Li, S., ... Huang, Y. (2014). Baicalein inhibits migration and invasion of gastric cancer cells through suppression of the TGF- $\beta$ signaling pathway. Molecular Medicine Reports, 10, 1999-2003.

De La O, J. P., \& Murtaugh, L. C. (2009). Notch and Kras in pancreatic cancer: At the crossroads of mutation, differentiation and signaling. Cell Cycle, 8, 1860-1864.

Egberts, J. H., Cloosters, V., Noack, A., Schniewind, B., Thon, L., Klose, S., .. . Trauzold, A. (2008). Anti-tumor necrosis factor therapy inhibits pancreatic tumor growth and metastasis. Cancer Research, 68, 1443-1450.

Fan, G., Zhang, Y., Jiang, X., Zhu, Y., Wang, B., Cao, W., .. . Gao, X. (2013). Anti-inflammatory activity of baicalein in LPS-stimulated RAW264.7 macrophages via estrogen receptor and NF-kappaB-dependent pathways. Inflammation, 36, 1584-1591.

Gao, Y., Snyder, S. A., Smith, J. N., \& Chen, Y. C. (2016). Anticancer properties of baicalein: A review. Medicinal Chemistry Research, 25, 1515-1523.

Garcia-Carracedo, D., Yu, C. C., Akhavan, N., Fine, S. A., Schonleben, F., Maehara, N., ... Su, G. H. (2015). Smad4 loss synergizes with TGFa overexpression in promoting pancreatic metaplasia, PanIN development, and fibrosis. PLoS ONE, 10, e0120851.

Grabliauskaite, K., Hehl, A. B., Seleznik, G. M., Saponara, E., Schlesinger, K., Zuellig, R. A., ... Graf, R. (2015). P21WAF1/Cip1 limits senescence and acinar-to-ductal metaplasia formation during pancreatitis. The Journal of Pathology, 235, 502-514.

Guerra, C., Schuhmacher, A. J., Cañamero, M., Grippo, P. J., Verdaguer, L., Pérez-Gallego, L., ... Barbacid, M. (2007). Chronic pancreatitis is essential for induction of pancreatic ductal adenocarcinoma by K-Ras oncogenes in adult mice. Cancer Cell, 11, 291-302.

Guo, Z., Hu, X., Xing, Z., Xing, R., Lv, R., Cheng, X., \& Liu, Z. (2015). Baicalein inhibits prostate cancer cell growth and metastasis via the caveolin-1/ AKT/mTOR pathway. Molecular and Cellular Biochemistry, 406, 111-119.

Halbrook, C. J., \& Crawford, H. C. (2015). Abstract A27: Redefining the role of Notch in acinar to ductal metaplasia. AACR Special Conference on Pancreatic Cancer: Innovations in Research and Treatment, New Orleans, LA, USA.

He, K., Yu, X., Wang, X., Tang, L., Cao, Y., Xia, J., \& Cheng, J. (2017). Baicalein and Ly294002 induces liver cancer cells apoptosis via regulating phosphatidyl inositol 3-kinase/Akt signaling pathway. [Epub ahead of print], http:// www.cancerjournal.net/preprintarticle.asp?id=192790; type $=0$

Helm, O., Held-Feindt, J., Grage-Griebenow, E., Reiling, N., Ungefroren, H., Vogel, I., ... Sebens, S. (2014). Tumor-associated macrophages exhibit pro- and anti-inflammatory properties by which they impact on pancreatic tumorigenesis. International Journal of Cancer, 135, 843-861.
Hughes, C. B., Grewal, H. P., Gaber, L. W., Kotb, M., El-din, A. B., Mann, L., \& Gaber, A. O. (1996). Anti-TNFa therapy improves survival and ameliorates the pathophysiologic sequelae in acute pancreatitis in the rat. American Journal of Surgery, 171, 274-280.

Johnston, W. C., Hoen, H. M., Cassera, M. A., Newell, P. H., Hammill, C. W., Hansen, P. D., \& Wolf, R. F. (2016). Total pancreatectomy for pancreatic ductal adenocarcinoma: Review of the National Cancer Data Base. HPB (Oxford), 18, 21-28.

Krejs, G. J. (2010). Pancreatic cancer: Epidemiology and risk factors. Digestive Diseases, 28, 355-358.

Lardon, J., \& Bouwens, L. (2005). Metaplasia in the pancreas. Differentiation, 73, 278-286.

Li, D., Xie, K., Wolff, R., \& Abbruzzese, J. L. (2004). Pancreatic cancer. The Lancet, 363, 1049-57.

Li, J., Wu, Y., Zhang, S., Zhang, J., Ji, F., Bo, W., .. . Li, Z. (2015a). Baicalein protect pancreatic injury in rats with severe acute pancreatitis by inhibiting pro-inflammatory cytokines expression. Biochemical and Biophysical Research Communications, 466, 664-669.

Li, J., Wu, Y., Zhang, S., Zhang, J., Ji, F., Bo, W., . . Li, Z. (2015b). Baicalein protects against pancreatic injury in rats with severe acute pancreatitis by inhibiting proinflammatory cytokine expression. The Official Journal of The International Hepato Pancreato Biliary Association, 17, 138.

Lian, H., Y. Hui, T. Xiaoping, T. Wei, X. Jiyi, \& Y. Xiaolan (2017). Baicalein suppresses the proliferation of human cervical cancer cells via Notch $1 /$ Hes signaling pathway. [Epub ahead of print], http://www. cancerjournal.net/preprintarticle.asp?id=204899; type $=0$

Liou, G. Y., Doppler, H., Necela, B., Krishna, M., Crawford, H. C., Raimondo, M., \& Storz, P. (2013). Macrophage-secreted cytokines drive pancreatic acinar-to-ductal metaplasia through NF-KB and MMPs. The Journal of Cell Biology, 202, 563-577.

Lowenfels, A. B., \& Maisonneuve, P. (2006). Epidemiology and risk factors for pancreatic cancer. Best Practice \& Research Clinical Gastroenterology, 20, 197-209.

Means, A. L., \& Logsdon, C. D. (2016). Acinar ductal metaplasia: Yap fills a gap. Gastroenterology, 151, 393-395.

Miyamoto, Y., Maitra, A., Ghosh, B., Zechner, U., Argani, P., lacobuzioDonahue, C. A., ... Leach, S. D. (2003). Notch mediates TGFa-induced changes in epithelial differentiation during pancreatic tumorigenesis. Cancer Cell, 3, 565-576.

Reding, T., Bimmler, D., Perren, A., Sun, L. K., Fortunato, F., Storni, F., \& Graf, R. (2006). A selective COX-2 inhibitor suppresses chronic pancreatitis in an animal model (WBN/Kob rats): Significant reduction of macrophage infiltration and fibrosis. Gut, 55, 1165-1173.

Reding, T., Wagner, U., Silva, A. B., Sun, L. K., Bain, M., Kim, S. Y., . . Graf, R. (2009). Inflammation-dependent expression of SPARC during development of chronic pancreatitis in WBN/Kob rats and a microarray gene expression analysis. Physiological Genomics, 38, 196-204.

Robinson, K., Vona-Davis, L., Riggs, D., Jackson, B., \& McFadden, D. (2006). Peptide YY attenuates STAT1 and STAT3 activation induced by TNFalpha in acinar cell line AR42J. Journal of the American College of Surgeons, 202, 788-796.

Ruffell, B., \& Coussens, L. M. (2015). Macrophages and therapeutic resistance in cancer. Cancer Cell, 27, 462-472.

Seleznik, G. M., Reding, T., Romrig, F., Saito, Y., Mildner, A., Segerer, S., .. . Heikenwalder, M. (2012). Lymphotoxin $\beta$ receptor signaling promotes development of autoimmune pancreatitis. Gastroenterology, 143, 1361-1374.

Shi, C., Hong, S.-M., Lim, P., Kamiyama, H., Khan, M., Anders, R. A., .. Eshleman, J. R. (2009). KRAS2 mutations in human pancreatic acinarDuctal metaplastic lesions are limited to those with PanIN: Implications for the human pancreatic cancer cell of origin. Molecular Cancer Research, 7, 230-236.

Shimosegawa, T., Kume, K., \& Satoh, K. (2009). Chronic pancreatitis and pancreatic cancer: Prediction and mechanism. Clinical Gastroenterology and Hepatology, 7, S23-8. 
Strobel, O., Dor, Y., Alsina, J., Stirman, A., Lauwers, G., Trainor, A., .. Thayer, S. P. (2007). In vivo lineage tracing defines the role of acinar-toductal transdifferentiation in inflammatory ductal metaplasia. Gastroenterology, 133, 1999-2009.

Sun, L. K., Reding, T., Bain, M., Heikenwalder, M., Bimmler, D., \& Graf, R. (2007). Prostaglandin E2 modulates TNF-alpha-induced MCP-1 synthesis in pancreatic acinar cells in a PKA-dependent manner. American Journal of Physiology Gastrointestinal and Liver Physiology, 293, G1196-G1204.

Sun, L. K., Wahl, P., Bilic, G., \& Wuthrich, R. P. (2001). CD44mediated cyclooxygenase-2 expression and thromboxane A2 production in RAW 264.7 macrophages. Inflammation Research, 50, 496-499.

Xue, J., Sharma, V., Hsieh, M. H., Chawla, A., Murali, R., Pandol, S. J., \& Habtezion, A. (2015). Alternatively activated macrophages promote pancreatic fibrosis in chronic pancreatitis. Nature Communications, 6, 7158.
Zhang, Y., Song, L., Cai, L., Wei, R., Hu, H., \& Jin, W. (2013). Effects of baicalein on apoptosis, cell cycle arrest, migration and invasion of osteosarcoma cells. Food and Chemical Toxicology, 53, 325-333.

Zhou, R. T., He, M., Yu, Z., Liang, Y., Nie, Y., Tai, S., \& Teng, C. B. (2017). Baicalein inhibits pancreatic cancer cell proliferation and invasion via suppression of NEDD9 expression and its downstream Akt and ERK signaling pathways. Oncotarget, 8, 56351.

How to cite this article: Pu W-L, Luo Y-Y, Bai R-Y, et al. Baicalein inhibits acinar-to-ductal metaplasia of pancreatic acinal cell AR42J via improving the inflammatory microenvironment. J Cell Physiol. 2018;233:5747-5755. https://doi.org/10.1002/jcp.26293 